\title{
The effect of dietary raw and autoclaved soya-bean protein fractions on growth, pancreatic enlargement and pancreatic enzymes in rats
}

\author{
By MICHAEL NAIM, ARIEH GERTLER AND YEHUDITH BIRK \\ Department of Agricultural Biochemistry, Faculty of Agriculture, The Hebrew University \\ of Jerusalem, Rehovot, Israel
}

(Received 15 April 1981-Accepted 9 September 1981)

\begin{abstract}
1. Raw soya-bean meal (RS) was fractionated into soya-bean lyophilized extract (SLE), soya-bean lyophilized residue (SLR), acid-precipitated proteins (APP) and whey proteins.

2. Trypsin (EC 3.4.21 .4) and chymotrypsin (EC 3 .4.21 .1) inhibitors (TI) were soluble at pH 8 and remained soluble after the extract was acidified to $\mathrm{pH} 4$.4. Except for whey, heating abolished, almost totally, their inhibiting activity.

3. Feeding SLE diet (high TI content) and APP diet (low TI content) resulted in growth depression below the RS level. Feeding the SLR diet resulted in an optimal growth. Feeding diets containing heated fractions improved the growth rate though not to the level observed with heated RS (HS) diet.

4. RS, SLE, APP and whey diets produced similar pancreatic enlargement which could be totally (RS, whey) or partially (SLE, APP) abolished by heating.

5. Feeding the RS diet reduced pancreatic amylase content. The factor responsible for this effect cofractionated with SLE and whey proteins.

6. Two groups of factors in the various diets were probably responsible for the elevation in pancreatic proteases. The first group were the heat-labile factors present in RS, SLE and whey whereas the second group resisted the heat treatment and were found in APP and SLR.

7. The results suggest that for optimal growth rate of rats, heat treatment should be given to the unfractionated soya-bean proteins rather than to the isolated fractions. The results further indicated that TI are not the only factors that can lead to pancreatic enlargement and changes in pancreatic enzymes composition.
\end{abstract}

The feeding of defatted raw soya-bean meal (RS) to different animal species inhibits growth, reduces protein digestibility, causes pancreatic enlargement, stimulates hypersecretion of pancreatic enzymes and causes other adversive physiological effects (Bielorai \& Bondi, 1963; Gertler et al. 1967; Liener, 1972; Rackis; 1974; Madar et al. 1976).

There is some controversy about the levels of enzymic activities in the pancreas of rats and chicks fed on RS diets $v$. those fed heated soya-bean-meal (HS) diets (Maayani \& Kulka, 1968; Konijn et al. 1970). In chicks, the addition of trypsin (EC 3 4 .21 .4) inhibitors derived from RS to HS diets increased the production of both proteolytic and amylolytic enzymes whereas in chicks given RS diets, only the increase in the proteolytic enzymes was obvious (Gertler \& Nitsan, 1970). The pancreas of rats fed on RS diets and then fasted contained less amylase and more trypsin and chymotrypsin $(E C 3.4 .21 .1)$ than those of rats fed on HS diets (Konijn et al. 1970). Nitsan \& Liener (1976) found that in the non-fasted state, the levels of trypsin, chymotrypsin and amylase in the pancreas of rats fed on RS diets were lower than in rats fed on HS diets. A $24 \mathrm{~h}$ period of fasting before killing equalized these levels. It was suggested that dietary trypsin inhibitors (TI) initiate increased enzyme secretion by a feedback mechanism. Due to the formation of a trypsin-TI complex in the intestine, proteolytic activity is reduced, and as a result, enhancement of protein synthesis in the pancreas occurs (Green \& Lyman, 1972; Niess et al. 1972). Pancreatic enzymes are rich in cystine and TI stimulated the conversion of methionine to cystine (Barnes \& Kwong, 1965). Thus, it was further hypothesized that the demand for more proteolytic enzymes could account for the reduction in pancreatic amylase observed in animals fed on RS diets. Methionine supplementation of RS diets increased the ratio, amylolytic: proteolytic enzymes in chick pancreas (Nitsan \& Gertler, 1972). 
In an attempt to isolate and determine the adverse effects of RS, it was fractionated into three main fractions: non-soluble residue, acid-precipitated proteins and whey proteins (Saxena et al. 1963; Rackis et al. 1963). The present study was undertaken to investigate the role of each of the fractions in producing the various effects, such as growth depression, pancreatic enlargement and changes in pancreatic digestive enzymes in rats. Experiments were further designed to explore whether a fractionation of soya-bean proteins before the heat treatment has a nutritional advantage or whether the presence of unfractionated proteins would be preferable.

\section{EXPERIMENTAL PROCEDURES}

Preparation of fractions. Defatted raw soya-bean flakes (Etz-Hazait, Israel) containing $440 \mathrm{~g}$ protein $/ \mathrm{kg}$ were ground to give raw soya-bean meal (RS). Fractionation was carried out according to Rackis et al. (1963), with some modifications. RS was extracted with water $(8: 1, \mathrm{w} / \mathrm{w})$ adjusted to $\mathrm{pH} 8$ at room temperature for $60 \mathrm{~min}$. The supernatant fraction was removed by centrifugation $\left(13000 \mathrm{~g}\right.$ at $2^{\circ}$ for $\left.20 \mathrm{~min}\right)$. The precipitate was re-extracted $(4: 1$, $\mathrm{w} / \mathrm{w})$ at $\mathrm{pH} 8$ for $60 \mathrm{~min}$ and centrifuged again. The precipitate was lyophilized to give soya-bean lyophilized residue (SLR). The water extracts were pooled and either lyophilized to give soya-bean lypophilized extract (SLE) or acidified to $\mathrm{pH} 4.4$ with $6 \mathrm{~m}$-hydrochloric acid and left overnight at $4^{\circ}$. The precipitate was then removed by centrifugation $(1060 \mathrm{~g}$ for $10 \mathrm{~min}$ ), washed with water at $\mathrm{pH} 4.4(10: 1, \mathrm{w} / \mathrm{w})$ for $60 \mathrm{~min}$, spun and lyophilized. The fraction obtained was designated the acid-precipitated proteins (APP). The supernatant fraction was brought to $\mathrm{pH} 8$ with $2.5 \mathrm{M}$-sodium hydroxide and left overnight at $4^{\circ}$. A small amount of precipitate (protein-phytate complex) was removed by decantation and centrifugation $\left(74000 \mathrm{~g}\right.$ for $10 \mathrm{~min}$ at $2^{\circ}$ ), and the supernatant fraction was lyophilized (whey-protein fractions). Heating of RS and various isolated fractions was performed by steam-heating in an autoclave at $120^{\circ}$ for $15 \mathrm{~min}$.

Chemical characterization of fractions. Protein was estimated as nitrogen $\times 6.25$ according to the Kjeldahl method (Horwitz, 1960).

Analysis of amino acids was performed after hydrolysis in constant boiling $\mathrm{HCl}\left(110^{\circ}\right.$, for $24 \mathrm{~h}$ in vacuo) using an amino acid analyser (Bio-Cal; model BC-200) with norleucine as the internal standard. Analysis of basic amino acids was performed on a short column (Moor et al. 1958; Spackman, 1963). Tryptophan was analyzed on the short column after alkali-hydrolysis in evacuated sealed tubes $\left(5 \mathrm{M}-\mathrm{NaOH}, 100^{\circ}, 5 \mathrm{~h}\right)$.

$\mathrm{TI}$ and chymotrypsin inhibitor content was determined titrimetrically with benzoylL-arginine ethylester hydrochloride (BAEE) and $N$-acetyl-L-tyrosine ethylester (ATEE) as substrates for trypsin and chymotrypsin respectively (Gertler \& Nitsan, 1970). One enzyme unit was defined as $1 \mu \mathrm{mol}$ substrate hydrolyzed/min at $25^{\circ}$. Trypsin inhibitor unit (TIU) and chymotrypsin inhibitor unit (CHIU) were defined as the number of enzyme units inhibited.

Animals and diets. Young albino male rats (a local strain supplied by the Volcani Research Institute, Rehovot) weighing 75-85 $\mathrm{g}$ were used. Rats were kept in a controlled room $\left(23 \pm 2^{\circ}\right)$ and housed in a grouping of six animals in wire-bottomed cages with continuous access to food and water. The rats were divided into groups by blocking and randomization (Box et al. 1978). Six male littermates born of the same mother were included in each block. Twelve rats (one from each litter) were taken for each feed treatment. Analyses of variance were performed and when the $F$ value was significant (at a $5 \%$ level or less), Duncan's test was applied for comparisons among the means. Since each feed treatment consisted of twelve rats housed in two different cages, possible housing effects were statistically tested using the Student's $t$ test for each treatment. No housing effects were found and the analyses of the results were therefore justified on an individual basis. During the experiments, the food 
Table 1. Yield, protein content and trypsin- and chymotrypsin-inhibiting activities of various raw soya-bean $(R S)$ fractions

\begin{tabular}{|c|c|c|c|c|c|c|c|}
\hline \multirow[b]{3}{*}{ Fraction } & \multirow{3}{*}{$\begin{array}{l}\text { Protein } \\
\text { content } \\
\text { (g/kg) }\end{array}$} & \multirow{2}{*}{\multicolumn{2}{|c|}{ Yield $(\mathrm{g} / \mathrm{kg})$}} & \multicolumn{4}{|c|}{ Inhibitory activity of: } \\
\hline & & & & \multirow{2}{*}{\multicolumn{2}{|c|}{$\begin{array}{l}\text { Trypsin Chymotrypsin } \\
\text { (/mg dry matter) }\end{array}$}} & \multirow{2}{*}{\multicolumn{2}{|c|}{$\begin{array}{c}\text { Trypsin Chymotrypsin } \\
(\% \text { of total } \dagger)\end{array}$}} \\
\hline & & Dry matter & Protein* & & & & \\
\hline RS & 440 & 1000 & 1000 & 3.40 & $6 \cdot 28$ & 100 & 100 \\
\hline SLE & 563 & 627 & 802 & $6 \cdot 24$ & $11 \cdot 25$ & 100 & 100 \\
\hline SLR & 327 & 287 & 211 & 0.17 & 0.52 & 1.5 & $2 \cdot 3$ \\
\hline Whey & 176 & 200 & 80 & $6 \cdot 87$ & $13 \cdot 75$ & $40 \cdot 3$ & $43 \cdot 7$ \\
\hline APP & 869 & 208 & 410 & 0.46 & 1.03 & $2 \cdot 8$ & 3.4 \\
\hline
\end{tabular}

SLE, soya-bean lyophilized extract; SLR, soya-bean lyophilized residue; APP, acid-precipitated proteins.

* Nitrogen $\times 6.25$.

$\dagger$ Calculated according to the yield of dry matter and expressed as percentage of RS.

cups were replenished daily and body-weight gain measurements were taken every $48 \mathrm{~h}$. At the end of the experiments (16-18 d), rats were fasted for $24 \mathrm{~h}$ and then killed by exsanguination. The pancreas was rapidly removed, freed from extraneous tissue, weighed and frozen at $-18^{\circ}$ until analysed. The composition of the experimental diets was $(\mathrm{g} / \mathrm{kg})$ : protein (RS, HS or RS fractions) 100 , DL-methionine 3 , soya-bean oil 80 , $\alpha$-cellulose 10 , choline chloride 2, vitamin mixture (Gertler et al. 1967) 23, salt mixture 59 (supplied mg/kg diet: $\mathrm{CaHPO}_{4} 21500, \mathrm{CaCO}_{3} 15000, \mathrm{KH}_{2} \mathrm{PO}_{4} 9000, \mathrm{KHCO}_{3} 3000, \mathrm{MgSO}_{4} 2500$ ), trace elements mixture 8000 (contained manganese 208, iodine 4, iron 12, copper 8 , cobalt 0.6 , zinc 160 , molybdenum 4 , sodium chloride 7600$)$, glucose - maize starch $(1: 1, w / w)$ to $1 \mathrm{~kg}$.

Determination of pancreatic digestive enzymes. The pancreas was homogenized in cold distilled water $\left(50 \mathrm{mg} / \mathrm{g}\right.$ with an Ultra-Turrax, centrifuged at $74000 \mathrm{~g}$ for $20 \mathrm{~min}$ at $2^{\circ}$. The supernatant fraction was removed and assayed within $2 \mathrm{~h}$ for various enzymic activities. The activation of zymogens were performed with enterokinase according to Gorril \& Thomas (1967). Then, the activities of trypsin and chymotrypsin were determined titrimetrically with BAEE and ATEE respectively as mentioned previously. One unit of activity was defined as one $\mu \mathrm{mol}$ substrate hydrolyzed $/ \mathrm{min}$ at $25^{\circ}$. Elastase (EC 3.4.21.11) was assayed by the Congo-red elastin technique as described by Gertler \& Nitsan (1970). One unit of activity was defined as the reciprocal of the time (min) required to obtain $50 \%$ digestion of Congo-red elastin multiplied by 100 . Amylase activity was determined by the method of Bernfeld (1955) with some modifications and without previous activation (Gertler \& Nitsan, 1970). One unit of activity was determined as $1 \mathrm{mg}$ maltose released in a $3 \mathrm{~min}$ reaction at $37^{\circ}$.

\section{RESULTS}

Chemical characterization of RS fractions. The contents and distribution of trypsin and chymotrypsin-inhibiting activities within various fractions are shown in Table 1. Some loss of dry matter and protein occurred when the water extract of RS was acidified. SLE and whey fractions contained the largest anti-proteolyctic activity. Thus, protease-inhibiting activity was soluble at $\mathrm{pH} 8$ and remained soluble after the extract was acidified to $\mathrm{pH} \mathrm{4.4}$. Except for the heated whey fraction (HWhey), autoclaving of RS and RS fractions resulted in an almost total reduction (values not shown) of inhibitory activity. HWhey still had approximately $7 \%$ trypsin-inhibiting and $13 \%$ chymotrypsin-inhibiting activity.

The amino acid composition of RS fractions is summarized in Table 2. As expected, SLE 
Table 2. Amino acids composition (umol amino acid/100 $\mathrm{mg}$ protein) of raw soya-bean $(R S)$ fractions

\begin{tabular}{|c|c|c|c|c|c|}
\hline Amino acids & RS & SLR & SLE & APP & Whey \\
\hline Aspartic & $91 \cdot 2$ & 86.8 & $92 \cdot 6$ & $90 \cdot 5$ & $99 \cdot 8$ \\
\hline Threonine & $32 \cdot 8$ & 42.9 & $30 \cdot 5$ & $30 \cdot 2$ & $37 \cdot 1$ \\
\hline Serine & 45.9 & $50 \cdot 5$ & $49 \cdot 3$ & $47 \cdot 7$ & $47 \cdot 3$ \\
\hline Glutamic & $132 \cdot 3$ & $115 \cdot 1$ & $137 \cdot 2$ & $134 \cdot 3$ & $104 \cdot 4$ \\
\hline Proline & $45 \cdot 4$ & $33 \cdot 3$ & $45 \cdot 5$ & $53 \cdot 3$ & $37 \cdot 7$ \\
\hline Glycine & $49 \cdot 1$ & $57 \cdot 7$ & $46 \cdot 8$ & $47 \cdot 5$ & 46.9 \\
\hline Alanine & 43.9 & 56.6 & $40 \cdot 1$ & $40 \cdot 8$ & 45.8 \\
\hline Half cystine & $10 \cdot 3$ & $6 \cdot 4$ & $13 \cdot 6$ & 9.8 & $22 \cdot 0$ \\
\hline Valine & $35 \cdot 1$ & $26 \cdot 8$ & 31.7 & $29 \cdot 3$ & $14 \cdot 7$ \\
\hline Methionine & $10 \cdot 3$ & $10 \cdot 6$ & 8.8 & $10 \cdot 9$ & 15.6 \\
\hline Isoleucine & 33.9 & $34 \cdot 6$ & $30 \cdot 3$ & $33 \cdot 9$ & $26 \cdot 3$ \\
\hline Leucine & 58.9 & $61 \cdot 5$ & $55 \cdot 3$ & $58 \cdot 2$ & 40.1 \\
\hline Tyrosine & $25 \cdot 9$ & $27 \cdot 9$ & $23 \cdot 3$ & $22 \cdot 9$ & $35 \cdot 9$ \\
\hline Phenylalanine & $31 \cdot 9$ & $33 \cdot 2$ & $32 \cdot 5$ & $33 \cdot 1$ & 35.0 \\
\hline Lysine & $43 \cdot 2$ & $43 \cdot 5$ & $38 \cdot 9$ & $43 \cdot 5$ & $55 \cdot 4$ \\
\hline Histidine & $16 \cdot 1$ & $20 \cdot 7$ & $16 \cdot 5$ & $18 \cdot 3$ & $21 \cdot 5$ \\
\hline Arginine & 44.9 & $41 \cdot 0$ & $50 \cdot 3$ & 45.6 & $52 \cdot 6$ \\
\hline Tryptophan & $6 \cdot 4^{*}$ & $6 \cdot 3^{*}$ & $9 \cdot 5^{*}$ & $6 \cdot 4^{*}$ & $9 \cdot 0 \dagger$ \\
\hline
\end{tabular}

SLR, soya-bean lyophilized residue; SLE, soya-bean lyophilized extract; APP, acid-precipitated proteins.

- Corrected for $16 \%$ loss during hydrolysis.

+ Corrected for $30 \%$ loss during hydrolysis.

which contained approximately $80 \%$ of RS proteins differed only slightly in amino acid content; more trypthophan and smaller amounts of lysine and methionine were found in SLE compared to RS. The APP fraction also had a similar amino acid pattern to that of RS. Compared to RS, the SLE fraction contained smaller amounts of glutamic acid, proline, half-cystine and valine and the whey fraction had small amounts of glutamic acid, proline, valine, isoleucine and leucine.

The effects of feeding various RS fractions on growth rate, pancreatic enlargement and food intake. Diet containing RS significantly reduced the growth rate as compared to HS (Table 3 , Expts 1,2). Growth inhibition was even more pronounced in the soluble fractions obtained from RS. Feeding the SLE diet resulted in almost total growth inhibition and the APP diet inhibited the growth significantly below the RS level. Growth inhibition down to the level obtained with the RS diet was also obtained by supplementing HS with whey proteins. For all three fractions, heating significantly improved the growth, although far below that with the HS diet, indicating that only a part of the deleterious fractors was heat unstable. On the other hand, feeding SLR resulted in an optimal growth rate and heating of this fraction markedly reduced its nutritional value.

The effect of various diets on pancreas enlargement could be only partially related to their effects on growth. As shown, diets based on RS, SLE, APP and whey-supplemented HS caused similar pancreas enlargement which could be totally (RS, whey) or partially (SLE, APP) abolished by heating. SLR had no effect on pancreas enlargement. Unexpectedly, an HSLR diet resulted in a slight but statistically significant increase in the pancreas size. So far, no explanation for this phenomenon can be suggested.

Although statistical evaluation of food intake could not be performed since the animals were not housed individually, it can be seen that the growth inhibition was paralleled by a decrease in food intake. However, in most instances, food intake differences among RS fractions were not substantially high. Noteworthy was the fact that the animals that suffered 


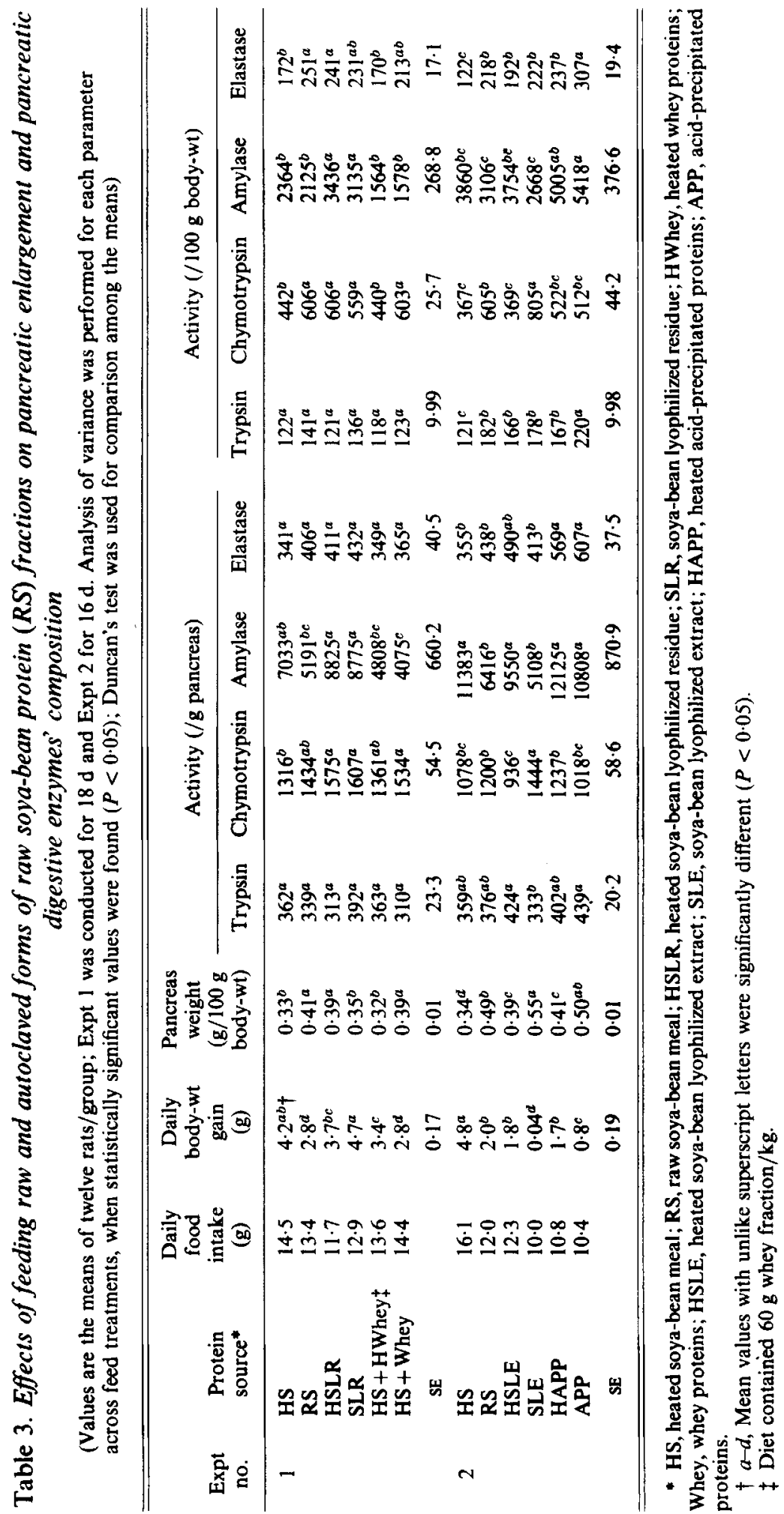


from growth inhibition were smaller and most probably ate less food for maintenance. Therefore, it seems that the decreased food intake could have been only partially responsible for growth inhibition.

The effect of feeding various fractions on the content of pancreatic enzymes. The effect of various diets on the enzymic content of pancreas was expressed either: per g pancreas or per $100 \mathrm{~g}$ body-weight; these methods of expression do not necessarily lead to similar results since the latter is positively affected by pancreas enlargement and by growth inhibition.

The most obvious effect caused by RS, as compared to an HS diet, was a remarkable decrease (although not statistically significant in one experiment) in the amylase level of the pancreas (Table 3). A similar decrease was also observed in diets containing SLE and whey, but not in those containing APP or SLR, thus indicating that the factor that exhibits this effect is most likely linked to whey proteins. Values expressed on a $100 \mathrm{~g}$ body-weight basis showed no comparable decrease or statistically-significant reduction.

The level of pancreatic proteolytic enzymes, when expressed per $g$ pancreas, was not affected by different diets except for an increase in elastase found in diets containing APP and heated APP. However, when the results were expressed per $100 \mathrm{~g}$ body-weight, it was found that all diets containing RS or other unheated fractions (except SLR) resulted in higher enzymic levels of chymotrypsin and elastase than the respective heated fractions. These differences were, in most instances, statistically significant. Trypsin content was affected in a similar way though the differences (except in one instance) were not significant.

\section{DISCUSSION}

The results support the suggestion Rackis et al. 1963; Gertler et al. 1967; Liener, 1972) that the growth inhibition observed in rats fed on RS diets are not directly related to the TI content. The APP diet, for example, which contained a low TI level, caused a strong growth inhibition similar to inhibitors-rich SLE diet. Furthermore, a considerable growth inhibition was still present following the feeding of heat-treated SLE and APP.

The present results substantiate, therefore, our former observations (Gertler et al. 1967) that the addition of pure trypsin inhibitors to HS diet results in pancreas enlargement but not in growth inhibition. Other growth inhibition factors must be responsible for poor growth as proposed earlier (Schingoethe et al. 1970). Furthermore, the results demonstrated that the presence of the natural combination of soya-bean proteins before heat treatment was nutritionally preferable to autoclaving the isolated fractions.

We preferred to use a mild-protein-restricted $(100 \mathrm{~g} / \mathrm{kg})$ diet as suggested for protein efficiency ratio (PER) tests (Rama Reo et al. 1960; Hegarty et al. 1977). The use of the standardized $100 \mathrm{~g}$ protein $/ \mathrm{kg}$ diet rather than the higher $150-180 \mathrm{~g} / \mathrm{kg}$ practical feeding levels often emphasized the role of growth- and metabolism-regulating factors that otherwise might be masked (Borchers, 1958).

Since animals in our experiments were not housed individually, statistical analyses for food intake and PER were not performed. One could see, however, that RS and some of the RS fractions might have produced a depression of food intake and thereby affected the growth rate and the relationship of weight gain to food intake (Naim et al. 1980). For example, the reduced growth rate caused by feeding SLE and APP diets could partially be explained by the reduced food intake.

Cysteine deficiency was suggested to be the reason for endogenous loss of sulphur amino acids (Barnes \& Kwong, 1965; Rackis, 1974) leading to an imbalance in metabolic amino acids pool and growth depression. Since methionine (converted in vivo to cystine) was added to the experimental diets of this study, the previously mentioned hypothesis could probably be ruled out. The $S$ amino acids are not the only amino acids limiting the nutritive value of RS. Tyrosine, threonine and valine, when added to the RS diets (Booth et al. 1960) 
resulted in a supplementary effect on growth. It is, however, questionable as to whether such amino acid imbalances were important in the present study. Another possible reason for the growth depression caused by feeding RS has been suggested by Nitsan \& Liener (1976). Their results indicated that there is a delay in amino acid absorption in rats fed on RS diets which could explain the low $\mathbf{N}$ retention.

The results indicated that the feeding of fractions containing high levels of TI, such as SLE and whey produced pancreatic enlargement. The role of TI in producing pancreatic enlargement was demonstrated before (Gertler et al. 1967). However, our results suggest the occurrence of additional heat-stable factors in APP (and heated APP) that cause pancreatic enlargement. The TI content of the APP diet was 7- to 8-fold lower than that of the whey-supplemented HS diet, but the effect on pancreas enlargement was similar or even higher, and unlike in the whey-supplemented diet, it was only partially abolished by heating. Although the nature of these factors is still unknown, they may cause pancreas enlargement by increased stimulation of cholecystokinine-pancreozymin (CCK) which controls physiologically pancreatic enzyme output (Johnson, 1974). It was shown that repeated injections of CCK caused pancreatic enlargement and increased enzyme secretion from the pancreas of rats (Rothman \& Wells, 1967).

The results of enzymic analyses agree with other studies indicating that there is a trend to have more proteases and less amylase in the pancreas of rats and chicks fed on RS diets (Maayani \& Kulka, 1968; Konijn et al. 1970). The inconsistency among different reports regarding these effects is probably due to the subjecting of animals to a $24 \mathrm{~h}$ fast before killing $v$. the non-fasting state. The effects of feeding RS on pancreatic enzymes composition is emphasized after fasting (Konijn et al. 1970; Nitsan \& Liener, 1976). Feeding of RS reduces the amylase content of the pancreas as reported formerly (Maayani \& Kulka, 1968; Konijn et al. 1970). Factor(s) responsible for this effect cofractionate with SLE and whey proteins, but not with APP. Heating of SLE but not of whey abolished this effect. It has been proposed that the reduction in pancreatic amylase content in chicks results from poor availability of methionine (Nitsan \& Gertler, 1972), but since our diet was supplemented with this amino acid, the present results do not support this hypothesis in rats.

The increase in pancreatic protease content, especially that of chymotrypsin and elastase, was emphasized when expressed on a per $100 \mathrm{~g}$ body-weight basis and occurred following the feeding of all RS fractions. It is apparent that two groups of factors in our diets were responsible for the elevation in pancreatic protease content. The first, composed mainly of trypsin inhibitors, is heat-labile and present in RS, SLE and whey, whereas the second resisted the heat treatment and was found in SLR and APP. The effects of the latter could be observed only after fractionation of RS.

In view of the results presented here and in previous papers (Maayani \& Kulka, 1968; Konijn et al. 1970), it seems the inverse relationships that exist between poor growth and between pancreas enlargement and total increased production of proteolytic enzymes (mainly chymotrypsin) may represent a physiological defence mechanism by which the affected animal tries to overcome growth inhibition.

The authors thank Dr Z. Nitsan for her interest in this work and Mrs G. Neta for her excellent technical assistance.

\section{REFERENCES}

Barnes, R. H. \& Kwong, E. (1965). J. Nutr. 86, 245.

Bernfeld, P. (1955). Meth. Enzym. 1, 149.

Bielorai, R. \& Bondi, A. (1963). J. Sci. Fd Agric. 14, 124.

Booth, A. N., Robbins, D. J., Ribelin, W. E. \& De Eds, F. (1960). Proc. Soc. exp. Biol. Med. 104, 681.

Borchers, R. (1958). J. Nutr. 66, 235. 
Box, G. E. P., Hunter, W. G. \& Hunter, J. S. (1978). Statistics for Experimenters. An Introduction to Design, Data Analysis and Model Building. New York: John Wiley.

Gertler, A., Birk, Y. \& Bondi, A. (1967). J. Nutr. 91, 358.

Gertler, A. \& Nitsan. Z. (1970). Br. J. Nutr. 24, 893.

Gorril, A. D. L. \& Thomas, J. W. (1967). Analyt. Biochem. 19, 211.

Green, G. M. \& Lyman, R. L. (1972). Proc. Soc. exp. Biol. Med. 140, 6.

Hegarty, P. V. J., Kim, S. H. \& Ahn, P. C. (1977). Growth 41, 221.

Horwitz, W. (1960). Official Methods of Analyses of the Association of Official Agricultural Chemists. Washington, DC: Association of Official Agricultural Chemists.

Johnson, L. R. (1974). In Gastrointestinal Physiology, p. 17 [E. D. Jacobson and L. L. Shanbour, editors]. Butterworths: University Park Press.

Konijn, A. M., Birk, Y. \& Guggenheim, K. (1970). J. Nutr. 100, 361.

Liener, I. E. (1972). In Soyabeans: Chemistry and Technology, vol. 1, p. 203 [A. K. Smith and S. J. Circle, editors]. Westport Conn: Avi Publishing Co.

Maayani, S. \& Kulka, R. S. (1968). J. Nutr. 96, 363.

Madar, Z., Tencer, Y., Gertler, A. \& Birk, Y. (1976). Nutr. Metab. 20, 234.

Moor, S., Spackman, D. H. \& Stein, W. H. (1958). Analyt. Chem. 30, 1185.

Naim, M., Brand, J. G., Kare, M. R., Kaufmann, N. A. \& Kratz, C. M. (1980). Physiol. Behav. $25,609$.

Niess, E., Ivy, C. A. \& Nesheim, M. C. (1972). Proc. Soc. exp. Biol. Med. 140, 6.

Nitsan, Z. \& Gertler, A. (1972). Br. J. Nutr. 27, 337.

Nitsan, Z. \& Liener, I. E. (1976). J. Nutr. 106, 300.

Rackis, J. J. (1974). J. Am. Oil Chem. Soc. 51, 161 A.

Rackis, J. J., Smith, A. K., Nash, A. M., Robbins, D. J. \& Booth, A. N. (1963). Cereal Chem. 40, 531.

Rama Reo, P. B., Metta, V. C., Morton, H. W. \& Johnson, B. C. (1960). J. Nutr. 71, 361.

Rothman, S. S. \& Wells, H. (1967). Am. J. Physiol. 213, 215.

Saxena, H. C., Jensen, L. S. \& McGinnis, J. (1963). Proc. Soc. exp. Biol. Med. 112, 101.

Schingoethe, D. J., Aust, S. D. \& Thomas, J. W. (1970). J. Nutr. 100, 739.

Spackman, D. H. (1963). Fedn Proc. Fedn Am. Socs exp. Biol. 22, 244. 